\title{
Attention Deficit Hyperactivity Disorder: Comparison of Medication Efficacy and Cost
}

\author{
Robert M. David \\ Karlen E. Luthy \\ Janelle L. B. Macintosh \\ Lacey M. Eden \\ Follow this and additional works at: https://scholarsarchive.byu.edu/studentpub \\ Part of the Nursing Commons
}

The College of Nursing showcases some of our best evidence based scholarly papers from graduate students in the Family Nurse Practitioner Program. The papers address relevant clinical problems for advance practice nurses and are based on the best evidence available. Using a systematic approach students critically analyze and synthesize the research studies to determine the strength of the evidence regarding the clinical problem. Based on the findings, recommendations are made for clinical practice. The papers are published in professional journals and presented at professional meetings.

\section{BYU ScholarsArchive Citation}

David, Robert M.; Luthy, Karlen E.; Macintosh, Janelle L. B.; and Eden, Lacey M., "Attention Deficit Hyperactivity Disorder: Comparison of Medication Efficacy and Cost" (2014). Student Works. 1. https://scholarsarchive.byu.edu/studentpub/1

This Master's Project is brought to you for free and open access by BYU ScholarsArchive. It has been accepted for inclusion in Student Works by an authorized administrator of BYU ScholarsArchive. For more information, please contact scholarsarchive@byu.edu, ellen_amatangelo@byu.edu. 
Attention Deficit Hyperactivity Disorder:

Comparison of Medication Efficacy and Cost

\author{
Robert M. David, FNP, MS \\ Brigham Young University \\ 500 SWKT \\ Provo, UT 84602 \\ bobdavid04@hotmail.com \\ Karlen E. Luthy, FNP, DNP \\ Brigham Young University \\ 457 SWKT \\ Provo, UT 84602 \\ beth_luthy@byu.edu \\ 1-801-422-6683
}

\author{
Janelle L. B. Macintosh, RN, PhD \\ Brigham Young University \\ 433 SWKT \\ Provo, UT 84602 \\ janelle-macintosh@byu.edu \\ Lacey M. Eden, FNP, MS \\ Brigham Young University \\ 535 SWKT \\ Provo, UT 84602 \\ lacey-eden@byu.edu \\ Renea L. Beckstrand, RN, PhD \\ Brigham Young University \\ 422 SWKT \\ Provo, UT 84602 \\ renea@byu.edu
}




\begin{abstract}
Although a common psychological disorder, pharmacological treatment of Attention Deficit Hyperactivity Disorder can be a costly endeavor. Among 4-5 year olds, methylphenidate is a safe, efficacious, and cost-effective option for short-, intermediate-, and long-acting medication options. Short-acting methylphenidate, intermediate-acting methylphenidate ER and SR, and long-acting methylphenidate LA are the most efficacious and cost-effective medications. Selection of non-stimulant medications should be based upon recommended guidelines rather than primarily on cost. For children incapable of swallowing pills, the most efficacious and costeffective treatments are short-acting dextroamphetamine liquid and long-acting methylphenidate LA capsules that can be opened and sprinkled over food.
\end{abstract}


Attention Deficit Hyperactivity Disorder:

A Comparison of Medication Efficacy and Cost

According to the United States Surgeon General, ${ }^{1}$ approximately $20 \%$ of children and adolescents in the United States (U.S.) exhibit signs or symptoms of a psychological or behavioral disorder. ${ }^{2}$ Attention Deficit Hyperactivity Disorder (ADHD) is one of the more common childhood psychological disorders affecting three to seven percent of school-age children. ${ }^{3}$ ADHD often presents in early childhood with symptoms of hyperactivity, impulsivity, and/or inattention. ${ }^{4,5}$ Associated with a variety of complications, untreated ADHD has the potential to impair a child’s cognitive, academic, behavioral, emotional, and social functioning. ${ }^{4,6}$ With full implementation of the Patient Protection and Affordable Care Act (PPACA) on January $1,2014,{ }^{7}$ health insurance coverage is anticipated to assist an additional 32 million previously uninsured citizens, thereby reducing the total number of uninsured in the U.S. ${ }^{8}$ and achieving near-universal coverage. ${ }^{7}$ A portion of the PPACA is designed to expand the eligibility for Medicaid by 15 million Americans, limit insurance exclusions, and mandate employers or individuals to purchase health insurance. ${ }^{9,7}$ While the PPACA alters health care coverage for many, it does not achieve universal coverage. ${ }^{9}$ In fact, it has been estimated that 24 million people will remain without health insurance coverage, even after January $1,2014 .^{7}$ This number could be higher, though, depending on how many states implement the Medicaid expansion program. ${ }^{10}$ In addition, "adults with incomes of 250-400 percent of poverty could remain at risk for...premiums that are high relative to their incomes." 11

Unfortunately, obtaining ADHD medication can be a costly endeavor for the family with an ADHD child, especially if the family is either uninsured or underinsured. Between 1994 and 2003, the price of ADHD medications in the U.S. rose by $285 \% .^{12}$ Considering the ever 
increasing costs of ADHD medications, “...providers and consumers should consider the costeffectiveness of a medication when making decisions about drug acceptance and coverage.”12 Moreover, because untreated children with ADHD may suffer social, behavioral, and emotional consequences; healthcare providers (HCPs) must carefully assess ADHD medication costs and efficacy to meet the needs of the child and family. The purpose of this review, therefore, is to evaluate ADHD medications to promote effective management of pediatric patients in relation to efficacy and expense.

\section{METHOD}

Several electronic database searches were conducted to review studies related to medications and treatments for ADHD. The databases search included MEDLINE, CINAHL, PsycINFO, UpToDate, and the Cochrane Library. Various websites were also reviewed, including the Affordable Care Act, American Academy of Child \& Adolescent Psychiatry, Centers for Disease Control and Prevention, Psych Central, CBS News, Healthline, National Institute of Mental Health, American Academy of Pediatrics, and United States Department of Health and Human Services.

Articles published in the past 10 years in English were included for review. Other inclusion criteria encompassed age groups related to children and adolescents, ages 0-18, and research articles using human studies. Systematic and integrative reviews of randomized controlled studies and drug trials related to ADHD were also obtained. While effective management of ADHD may incorporate behavioral, pharmacological, and multimodal approaches, only pharmacological treatment options were included for review. Articles which focused on adult treatment of ADHD or articles of ADHD diagnoses attached to other comorbidities such as psychiatric or cardiac issues were also excluded. Search terms included: 
ADHD, Attention Deficit Hyperactivity Disorder, medication, efficacy, cost, pediatric, treatment, effectiveness, safety, side effects, expense, children, adolescent, drug therapy, and risk.

\section{RESULTS}

\section{Stimulants}

Stimulants are the first-line treatment option for $75-90 \%$ of children suffering with the hyperactivity, impulsivity, and inattention of ADHD. ${ }^{13-16}$ Despite a variety of preparations for the treatment of ADHD—short-acting, intermediate-acting, and long-acting — there is no evidence showing a clear benefit to using one stimulant over another in any of the preparations. ${ }^{17-21}$ It is possible, however, that individual children will respond more favorably to one stimulant or preparation. ${ }^{22}$ Therefore, clinical decisions guiding the use of a particular stimulant remains a point of caregiver preference with consideration of the patient's ability to swallow pills, needs regarding duration of action, age, co-morbidities, potential contraindications, and medication cost. ${ }^{13}$

Short-acting stimulants. Short-acting stimulants last approximately 3-6 hours and often require dosing more frequently than once per day. While the disadvantages from frequent dosing of short-acting stimulants include the possible disruption of the child's school day and confidentiality, ${ }^{23}$ the frequent dosing also allows for greater precision when dosing. A list of short-acting stimulants, available doses, and associated costs is presented in Table 1.

Dextroamphetamine. Dextroamphetamine is available in tablet or liquid form and as the brand names Dexedrine (tablet), Dextrostat (tablet), Procentra (liquid), and Zenzedi (tablet). The medication is commonly prescribed more than once per day. All forms of dextroamphetamine are available as generic except the $2.5 \mathrm{mg}$ and $7.5 \mathrm{mg}$ doses which are only available as the brand name Zenzedi. Other available dosing options of dextroamphetamine include $5 \mathrm{mg}, 10 \mathrm{mg}$, 
$15 \mathrm{mg}, 20 \mathrm{mg}$, and $30 \mathrm{mg}$. The cost of Dexedrine and Dextrostat are the same $-\$ 133.05$ for 60 of the $5 \mathrm{mg}$ tablets. ${ }^{24} \mathrm{In}$ comparison, $300 \mathrm{ml}$ of $5 \mathrm{mg} / 5 \mathrm{ml}$ Procentra is $\$ 414.00 .^{24}$ For 60 tablets of the $5 \mathrm{mg}$ Zenzedi, the cost is $\$ 224.25 .^{24}$ All of the short-acting dextroamphetamine preparations are approved by the United States Food and Drug Administration (FDA) for use in children over the age of 3 years. ${ }^{25}$

Methamphetamine. Desoxyn is the brand name preparation for methamphetamine and is available only in a $5 \mathrm{mg}$ tablet that is commonly dosed twice per day. Methamphetamine is FDA approved for use in children 6 years old and older. ${ }^{25}$ For 60 tablets of 5 mg methamphetamine, the cost is $\$ 334.78,{ }^{26}$ almost triple the cost of the dextroamphetamines.

Methylphenidate. Methylphenidate is available in several forms: tablet (brand name Ritalin), chewable tablet (brand name Methylin), and liquid (Methylin), ${ }^{24}$ all of which may need dosing twice a day. ${ }^{13,23}$ All formulations of methylphenidate are FDA approved for use in children 6 years old and older and all brand names are available as generics. ${ }^{25}$ Ritalin (tablet) is available in $5 \mathrm{mg}, 10 \mathrm{mg}$, and $20 \mathrm{mg}$ doses. Methylin (chewable tablet) is available in $2.5 \mathrm{mg}, 5$ mg, and $10 \mathrm{mg}$ doses. Finally, as a liquid Methylin is available in $5 \mathrm{mg} / 5 \mathrm{ml}$ and $10 \mathrm{mg} / 5 \mathrm{ml}$ forms. Methylphenidate tablets (Ritalin) costs $\$ 33.55$ for 60 of the $5 \mathrm{mg}$ tablets, ${ }^{24}$ a fraction of the cost of dextroamphetamines and methamphetamines. The chewable methylphenidate tablets (Methylin) are more costly with a price of $\$ 268.80$ for 605 mg tablets. ${ }^{24}$ The liquid form of methylphenidate (Methylin) costs $\$ 291.00$ for $300 \mathrm{ml}$ of the $10 \mathrm{mg} / 5 \mathrm{ml}$ dose. $^{24}$

Dexmethylphenidate. Focalin is the common brand name for dexmethylphenidate, a tablet that is also available as a generic. Like Zenzedi (dextroamphetamine), dexmethylphenidate is available in smaller doses starting at $2.5 \mathrm{mg}$ tablets and increasing in dosing to $5 \mathrm{mg}$ and $10 \mathrm{mg}$ tablets. ${ }^{13,27}$ Dexmethylphenidate is also approved for use in children 6 years of age or older. ${ }^{25}$ 
Currently, dexmethylphenidate is available for $\$ 46.20$ for 60 tablets of the $5 \mathrm{mg}$ dose, ${ }^{24}$ which is similar to the cost of Ritalin.

Dextroamphetamine/amphetamine. The generic form of Adderall, dextroamphetamine/amphetamine is FDA approved for use in children aged 3 years old and older. ${ }^{28}$ Dextroamphetamine/amphetamine generic is available in tablet form and in dosing increments of $5 \mathrm{mg}, 7.5 \mathrm{mg}, 10 \mathrm{mg}, 12.5 \mathrm{mg}, 15 \mathrm{mg}, 20 \mathrm{mg}$, and $30 \mathrm{mg} .{ }^{27}$ The current cost for 60 $5 \mathrm{mg}$ tablets is $\$ 72.47 .^{24}$

Intermediate-acting stimulants. Intermediate-acting ADHD stimulants bridge the gap between short-acting and long-acting medications with an average duration of 6-10 hours. As extended release tablets, intermediate-acting stimulants are not to be chewed, crushed, or divided. ${ }^{24,27}$ A list of intermediate-acting stimulants, available doses, and associated costs is presented in Table 2.

Methylphenidate. None of the methylphenidate intermediate-acting stimulants are recommended for use in children under 6 years old. ${ }^{25}$ Available formulations of immediateacting methylphenidate include methylphenidate ER (Metadate ER), methylphenidate SR (Ritalin SR), and methylphenidate CD (Metadate CD). ${ }^{23}$ Methylphenidate ER and SR formulations are available in tablet form and are only offered in a 20 mg dose. Methylphenidate $\mathrm{CD}$ is available as capsules and offered in $10 \mathrm{mg}, 20 \mathrm{mg}, 30 \mathrm{mg}, 40 \mathrm{mg}, 50 \mathrm{mg}$, and $60 \mathrm{mg}$ doses. The cost of methylphenidate ER and SR are identical— $\$ 41.31$ for 30 of the $20 \mathrm{mg}$ tablets. $^{24}$ The cost of methylphenidate CD is $\$ 112.50$ for 3020 mg capsules. ${ }^{24}$

Long-acting stimulants. Long-acting stimulants are typically taken only once a day and have a duration ranging from 6-12 hours. ${ }^{23}$ As with all extended release medications, the pills or capsules should not be divided, crushed or chewed. ${ }^{24}$ The long-acting stimulants have the most 
variety regarding route of administration, including tablets, capsules, liquid, and a transdermal patch. All of the long-acting stimulants are FDA approved for use in children who are 6 years and older. ${ }^{25}$ A list of long-acting stimulants, available doses, and associated costs can be found in Table 3.

Dextroamphetamine. The brand name preparation of dextroamphetamine ER is Dexedrine Spansules and is available as capsules in $5 \mathrm{mg}, 10 \mathrm{mg}$, and $15 \mathrm{mg}$ doses. For children who find it difficult to swallow a capsule, dextroamphetamine ER can be opened and sprinkled over a small amount of applesauce as long as the beads are not chewed or crushed. ${ }^{13}$ The cost for $3015 \mathrm{mg}$ capsules is $\$ 118.55 .^{24}$

Methylphenidate. Methylphenidate LA (Ritalin LA), methylphenidate ER (Concerta), methylphenidate transdermal (Daytrana), and methylphenidate XR (Quillivant XR) are all longacting with a 10-12 hour duration. ${ }^{13,15}$ The available doses of methylphenidate LA include 10 mg, $20 \mathrm{mg}, 30 \mathrm{mg}$, and $40 \mathrm{mg}$ capsules. Methylphenidate ER is available in $18 \mathrm{mg}, 27 \mathrm{mg}, 36$ mg, $54 \mathrm{mg}$, and $72 \mathrm{mg}$ tablets. The methylphenidate transdermal patch can only be purchased as the brand name-Daytrana—in $10 \mathrm{mg}, 15 \mathrm{mg}, 20 \mathrm{mg}$, and $30 \mathrm{mg}$ dosing increments. The only long-acting stimulant in liquid form is methylphenidate XR which is only sold as the brand name Quillivant XR with one available dose $-25 \mathrm{mg} / 5 \mathrm{ml}$. Methylphenidate LA can be purchased for $\$ 112.50$ for 3020 mg capsules. ${ }^{24}$ The cost for 30 tablets of 18 mg methylphenidate ER is $\$ 141.30 .^{24}$ Not surprisingly, Daytrana, which is only available as a brand name medication, is more expensive than the other long-acting methylphenidate preparations at \$246.88 for 30 patches of the $20 \mathrm{mg}$ dose. ${ }^{24}$ Quillivant XR is $\$ 238.40$ for $120 \mathrm{ml}$ of the $25 \mathrm{mg} / 5 \mathrm{ml} \mathrm{dose.}{ }^{26}$

Dextroamphetamine/amphetamine. Adderall XR, the brand name for generic dextroamphetamine/amphetamine XR, is indicated for treatment of ADHD in children over the 
age of 6 years old. ${ }^{15}$ Available as a capsule, dextroamphetamine/amphetamine XR is offered at dosing increments of $5 \mathrm{mg}, 10 \mathrm{mg}, 15 \mathrm{mg}, 20 \mathrm{mg}, 25 \mathrm{mg}$, and $30 \mathrm{mg}$. The cost for 30 capsules of $20 \mathrm{mg}$ dextroamphetamine/amphetamine $\mathrm{XR}$ is $\$ 248.52 .{ }^{24}$

Lisdexamfetamine. As with all other long-acting stimulants, lisdexamfetamine (Vyvanse) is only FDA approved for use in children over the age of 6 years old. Lisdexamfetamine is a capsule available in $20 \mathrm{mg}, 30 \mathrm{mg}, 40 \mathrm{mg}, 50 \mathrm{mg}, 60 \mathrm{mg}$, and $70 \mathrm{mg}$ doses. Preferably the medication is swallowed whole, although if the child has difficulty swallowing the capsule, it may be opened and poured into a glass of water prior to consumption. ${ }^{24,27}$ A generic form is currently unavailable for Vyvanse; the cost of $3020 \mathrm{mg}$ capsules is $\$ 212.70$. $^{24}$

Dexmethylphenidate ER. Dexmethylphenidate ER, also available as the brand name Focalin XR, is approved for use in children who are at least 6 years of age. ${ }^{25}$ The generic preparation of dexmethylphenidate ER is only available in $15 \mathrm{mg}, 30 \mathrm{mg}$, and $40 \mathrm{mg}$ doses. While dexmethylphenidate ER is also available in dosing increments of $5 \mathrm{mg}, 10 \mathrm{mg}, 20 \mathrm{mg}, 25$ mg, and $35 \mathrm{mg}$, these doses are only available for purchase as the brand name, Focalin XR. While intended to be swallowed whole, the capsule may also be opened and sprinkled on applesauce. The cost for 30 capsules of the $20 \mathrm{mg}$ dose is $\$ 241.50 .^{24}$

\section{Non-stimulants}

Generally, non-stimulants are not considered first-line ADHD interventions ${ }^{13,22,16}$; however, for patients who fail to respond to stimulants, for whom stimulants are contraindicated, or for patients in whom other comorbidities exist (e.g. tic disorder), a non-stimulant may be a viable treatment option. ${ }^{13,22,16}$ Non-stimulant treatment options for ADHD include atomoxetine (Strattera) which is a norepinephrine reuptake inhibitor and guanfacine (Intuniv) and clonidine ER (Kapvay) which are both alpha-2 adrenergic agonists. While each of the non-stimulant 
medications are FDA approved for use in children aged 6 years and older, the AAP recommends a stepwise treatment of atomoxetine, guanfacine and then clonidine ER, in that specific order. ${ }^{29}$ One disadvantage of non-stimulant ADHD medications is that achieving a therapeutic response takes time, sometimes several weeks before improvement is seen, whereas stimulants act quickly and results may be perceived to be immediate. ${ }^{30}$ A list of non-stimulants, available doses, and associated costs can be found in Table 4.

Norepinephrine reuptake inhibitors. Atomoxetine is the generic form of Strattera, which is available in $10 \mathrm{mg}, 18 \mathrm{mg}, 25 \mathrm{mg}, 40 \mathrm{mg}, 60 \mathrm{mg}, 80 \mathrm{mg}$, and $100 \mathrm{mg}$ doses. The capsules may be administered as a one-time morning dose or as divided doses in the morning and late afternoon or early evening. ${ }^{24,27}$ The duration of atomoxetine is approximately 10-12 hours. ${ }^{13}$ The lowest dose, $10 \mathrm{mg}$, can be purchased for $\$ 240.44$ for 30 capsules. $^{24}$

Alpha-2 adrenergic agonists. Additionally, there are two options for ADHD treatment with alpha-2 adrenergic agonists: guanfacine (Intuniv) and clonidine ER (Kapvay). Guanfacine (Intuniv) is indicated as an alternative to stimulant use in the treatment of ADHD, although it should only be prescribed after failing on a trial of atomoxetine. ${ }^{29}$ The duration of guanfacine is at least a 10-12 hour duration and is recommended as a once daily medication taken in either the morning or evening. ${ }^{25}$ The price of guanfacine is $\$ 16.50$ for 30 tablets of the lowest dose, $1 \mathrm{mg} .^{24}$

Clonidine ER can be prescribed as $0.1 \mathrm{mg}$ or $0.2 \mathrm{mg}$ tablets and has a duration of at least 10-12 hours. While clonidine ER is FDA approved as a non-stimulant treatment option, a trial should be attempted only after the patient has first failed on atomoxetine and guanfacine. ${ }^{29}$ The lowest dose of clonidine ER, $0.1 \mathrm{mg}$, can be purchased for $\$ 141.60$ for 30 tablets. $^{24}$ 


\section{IMPLICATIONS FOR PRACTICE}

While there are no intermediate- or long-acting ADHD medications approved for use in preschool-aged children aged 3-5 years, there are two main classes of short-acting ADHD medications that have received approval from the FDA for use in this age group, namely dextroamphetamine and dextroamphetamine/amphetamine. ${ }^{27}$ However, despite the FDA's approval, the American Academy of Pediatrics (AAP) does not recommend the use of dextroamphetamine or dextroamphetamine/amphetamine in preschool-aged children ${ }^{29}$ with the rationale that the FDA approval of these ADHD medications in children younger than 6 years old took place during a time when less stringent criteria was required. Thus, even though dextroamphetamine and dextroamphetamine/amphetamine have FDA approval for use in children as young as 3 years old, the empirical evidence regarding the safety and efficacy of these short-acting stimulants in preschoolers is lacking. ${ }^{29}$

Most of the stimulant medication studies in preschoolers with ADHD have been conducted with methylphenidate, a medication proven to be safe and efficacious in preschool children. Notwithstanding the recommendation to use methylphenidate off-label in preschool children with ADHD, its use is recommended in children 4-5 years old and after trying behavior interventions first. ${ }^{13,29}$ According to Krull ${ }^{13}$, children suffering from ADHD who are younger than 6 years old should also be managed by or in consultation with a specialist.

\section{Recommendations for Preschoolers with ADHD}

Three-year old children are difficult to diagnose and have limited options for stimulant medications. ${ }^{29}$ Thus, we recommend the diagnosis and management of 3 year old children with ADHD in coordination with a specialist. Because methylphenidate has been well studied and is recommended in guidelines set forth by the AAP for ADHD treatment in preschoolers ages 4-5 
years old, we cautiously recommend its use as a first-line stimulant medication in this age group. Besides being recommended as the first-line stimulant medication for children ages 4-5, it is also the most cost-effective option of all the short-acting stimulants. The lowest available dose, however, is a $5 \mathrm{mg}$ tablet that is unscored, meaning that it may not accurately split with a pill splitter. Thus, methylphenidate should be prescribed in 4-5 year old preschoolers only when the $5 \mathrm{mg}$ dose can be swallowed whole.

\section{Recommendations for Children Unable to Swallow Pills}

Children over the age of 6 years who are unable to swallow pills whole should be provided other options. Among the short-acting stimulants, the most cost-effective option is methylphenidate (Methylin) chewable tablets at \$268.80 for 605 mg tablets. Non-tablet options, however, are unavailable in the intermediate-acting stimulant category. If a long-acting stimulant is clinically indicated, the most cost-effective option is dextroamphetamine ER, which is a capsule that can be opened and sprinkled over applesauce.

\section{Recommendations for Short-, Intermediate-, and Long-acting Stimulants}

Since there is no clear difference in efficacy of short-, intermediate-, and long-acting stimulants, cost should be an important factor when selecting a stimulant medication for children age 6 years and older. The most cost-effective short-acting stimulant is methylphenidate (Ritalin) at $\$ 33.55$ for 60 of the $5 \mathrm{mg}$ tablets. The most cost-effective intermediate-acting stimulant is either methylphenidate ER or methylphenidate SR at a cost of $\$ 41.31$ for 30 of the $20 \mathrm{mg}$ tablets. For long-acting stimulants, methylphenidate LA is the most cost-effective at $\$ 112.50$ for 30 of the $20 \mathrm{mg}$ capsules, although for patients who cannot tolerate methylphenidate, dextroamphetamine ER is also cost-effective at \$118.55 for 30 of the $15 \mathrm{mg}$ capsules. 


\section{Recommendations for Non-stimulants}

While guanfacine is the most cost-effective option for non-stimulant treatment of ADHD, it is not the first-line non-stimulant medication as recommended by the AAP. While cost is an important consideration, our recommendation for non-stimulant medications is primarily based on AAP guidelines. ${ }^{29}$ Thus, selection of a non-stimulant medication for the treatment of ADHD should be independent of cost, with atomoxetine first (\$240.44 for 30 of $10 \mathrm{mg}$ capsules), guanfacine second ( $\$ 16.50$ for 30 of the $1 \mathrm{mg}$ tablets), and finally, clonidine ER ( $\$ 141.60$ for 30 of the $0.1 \mathrm{mg})$.

\section{CONCLUSION}

ADHD is a commonly occurring condition in childhood; however, treatment of ADHD symptoms with medications can be a costly endeavor for the family of the pediatric ADHD patient. Consequently, HCPs should stay informed regarding the efficacy and cost of ADHD medications appropriate for use in pediatric patients. With careful consideration of medication cost and efficacy, HCPs can positively influence pharmacological treatment compliance for children with ADHD, which then influences the child's ability to function cognitively, academically, behaviorally, emotionally and socially. 


\section{References}

1. United States Department of Health and Human Services. Mental health: a report of the surgeon general. http://profiles.nlm.nih.gov/ps/access/NNBBHS.pdf. Published 1999. Accessed June 14, 2014.

2. Currie J, Stabile M. Child mental health and human capital accumulation: the case of ADHD. J Health Econ. 2006;25(6):1094-1118. doi:10.1016/j.jhealeco.2006.03.001.

3. Centers for Disease Control and Prevention. Attention-deficit/hyperactivity disorder (ADHD). http://www.cdc.gov/ncbddd/adhd/data.html\#1. Updated November 13, 2013. Accessed June 14, 2014.

4. Akinbami L, Liu X, Pastor P, Reuben, C. Attention deficit hyperactivity disorder among children aged 5-7 years in the United States, 1998-2009. NCHS Data Brief. 2011;70:1-8.

5. American Academy of Child \& Adolescent Psychiatry. Children who can’t pay attention/attention-deficit/hyperactivity disorder. http://www.aacap.org/AACAP/Families_and_ Youth/Facts_for_Families/Facts_for_Families_Pages/Children_Who_Cant_Pay_Attention_ADH D_06.aspx. Updated October 2013. Accessed June 14, 2014.

6. Fulton B, Scheffler R, Hinshaw S, et al. National variation of ADHD diagnostic prevalence and medication use: Health care providers and education policies. Psychiatr Serv. 2009;60(8):1075-1083. doi:10.1176/appi.ps.60.8.1075.

7. Rosenbaum S. Patient Protection and Affordable Care Act: implications for public health policy and practice. Public Health Rep. 2011;126(1):130-135.

8. Jackson J, Nolen, J. Health care reform bill summary: a look at what's in the bill. CBS News. http://www.cbsnews.com/8301-503544_162-20000846-503544.html. Published March 21, 2010. Accessed June 14, 2014.

9. Boninger J, Gans B, Chan L. Patient protection and affordable care act: potential effects on physical medicine and rehabilitation. Arch Phys Med Rehabil. 2012;93(6):939-934. doi:10.1016/j.apmr.2012.03.014.

10. Henry J. Kaiser Family Foundation. Medicaid and the uninsured. http://www.kff.org/ uninsured/upload/7806-05.pdf. Published September 1, 2012. Accessed June 14, 2014.

11. Schoen C, Doty MM, Robertson RH, Collins SR. Affordable Care Act reforms could reduce the number of underinsured US adults by 70 percent. Health Aff. 2011;30(9):1762-1771. doi:10.1377/hlthaff.2011.0335.

12. Lang H, Scheffler R, Hu T. The discrepancy in attention deficit hyperactivity disorder (ADHD) medications diffusion: 1994-2003—a global pharmaceutical data analysis. Health Policy. 2010;97(1):71-78. doi:10.1016/j.healthpol.2010.03.005. 
13. Krull KR. Pharmacology of drugs used to treat attention deficit hyperactivity disorder in children and adolescents. In: Augustyn M, Torchia M, eds. UpToDate. Waltham, MA: UpToDate; 2014.

15. Wigal S. Efficacy and safety limitations of attention-deficit hyperactivity disorder pharmacotherapy in children and adults. CNS Drugs. 2009;23(Suppl 1):21-31. doi:10.2165/00023210-200923000-00004.

16. Wolraich M, Brown L, Brown RT, et al. ADHD: clinical practice guideline for the diagnosis, evaluation, and treatment of attention-deficit/hyperactivity disorder in children and adolescents. Pediatrics. 2011;128(5):1007-1022. doi:10.1542/peds.2011-2654.

17. Brown RT, Amler RW, Freeman WS, et al. Treatment of attention-deficit/hyperactivity disorder: overview of the evidence. Pediatrics. 2005;115(6):e749-e757.doi:10.1542/peds.20042560.

18. Coghill D, Banaschewski T, Zuddas A, Pelaz A, Gagliano A, Doepfner, M. Long-acting methylphenidate formulations in the treatment of attention-deficit/hyperactivity disorder: a systematic review of head-to-head studies. BMC Psychiatry. 2013;13(237). doi:10.1186/1471244X-13-237.

19. King, S., Griffin, S., Hodges, Z., et al. A systematic review and economic model of the effectiveness and cost-effectiveness of methylphenidate, dexamfetamine and atomoxetine for the treatment of attention deficit hyperactivity disorder in children and adolescents. Health Technol Assess. 2006;10(23):iii-iv, xii-146. doi:10.3310/hta10230.

20. Maldonado R. Comparison of the pharmacokinetics and clinical efficacy of new extended release formulations of methylphenidate. Expert Opin Drug MetabToxicol. 2013;9(8):10011014. doi:10.1517/17425255.2013.786041.

21. Stein M, Waldman I, Charney E, et al. Dose effects and comparative effectiveness of extended release dexmethylphenidate and mixed amphetamine salts. J Child Adolesc Psychopharmacol. 2011;21(6):581-588. doi:10.1089/cap.2011.0018.

22. Shier AC, Reichenbacher T, Ghuman HS, Ghuman JK. Pharmacological treatment of attention deficit hyperactivity disorder in children and adolescents: Clinical strategies. J Cent Nerv Syst Dis. 2013;5:1-17. doi:10.4137/JCNSD.S669.

23. WebMD. ADD \& ADHD health center: ADHD medication chart. http://www.webmd.com/ add-adhd/adhd-medication-chart. Updated May 10, 2014. Accessed June 14, 2014.

24. Drugs.com. http://www.drugs.com. Updated 2014. Accessed June 14, 2014.

25. Epocrates Premium ${ }^{\circledR V}$ Version. San Mateo, CA: Epocrates, Inc., 2014.

http://www.epocrates.com. Accessed June 14, 2104. 
26. Goodrx.com. http://www.goodrx.com. Updated 2014. Accessed June 14, 2014.

27. PDR.net. http://www.pdr.net. Accessed June 14, 2014.

28. United States Food and Drug Administration. Adderall (C11). http://www.accessdata.fda.gov/drugsatfda_docs/label/2007/011522s040lbl.pdf. Updated March 2007. Accessed June 14, 2014.

29. Subcommittee on Attention-deficit/Hyperactivity Disorder; Steering Committee on Quality Improvement and Management, Wolraich M, Brown L, et al. ADHD: clinical practice guideline for the diagnosis, evaluation, and treatment of attention-deficit/hyperactivity disorder in children and adolescents. Pediatrics. 2011;128(5):1007-1022. doi:10.1542/peds.2011-2654.

30. Hanwella R, Senanayake M, de Silva V. Comparative efficacy and acceptability of methylphenidate and atomoxetine in treatment of attention deficit hyperactivity disorder in children and adolescents: a meta-analysis. BMC Psychiatry. 2011;11(176). doi:10.1186/1471244X-11-176. 
Table 1. Cost Comparison of Short-acting Stimulants

\begin{tabular}{|c|c|c|c|c|c|c|}
\hline $\begin{array}{l}\text { Availability } \\
\text { as Generic }\end{array}$ & Generic Name & Brand Name & Available Doses & Type & Age & Cost \\
\hline Yes $^{*}$ & Dextroamphetamine & $\begin{array}{l}\text { Dexedrine } \\
\text { Dextrostat } \\
\text { Procentra } \\
\text { Zenzedi }\end{array}$ & $\begin{array}{l}5,10 \\
5,10 \\
5 \mathrm{mg} / 5 \mathrm{ml} \\
2.5,5,7.5,10,15,20,30\end{array}$ & $\begin{array}{l}\text { Tablet } \\
\text { Tablet } \\
\text { Liquid } \\
\text { Tablet }\end{array}$ & $\begin{array}{l}\geq 3 \\
\geq 3 \\
\geq 3 \\
\geq 3\end{array}$ & $\begin{array}{l}60 \mathrm{tab} \text { of } 5 \mathrm{mg} \$ 133.05^{24} \\
60 \mathrm{tab} \text { of } 5 \mathrm{mg} \$ 133.05^{24} \\
300 \mathrm{ml} \text { of } 5 / 5 \mathrm{ml} \$ 414.00^{24} \\
60 \mathrm{tab} \text { of } 5 \mathrm{mg} \$ 224.25^{24}\end{array}$ \\
\hline Yes & Methamphetamine & Desoxyn & 5 & Tablet & $\geq 6$ & 60 tab of $5 \mathrm{mg} \$ 334.78^{26}$ \\
\hline Yes & Methylphenidate & $\begin{array}{l}\text { Ritalin } \\
\text { Methylin } \\
\text { Methylin }\end{array}$ & $\begin{array}{l}5,10,20 \\
2.5,5,10 \\
5 / 5 \mathrm{ml} 10 / 5 \mathrm{ml}\end{array}$ & $\begin{array}{l}\text { Tablet } \\
\text { Chewable } \\
\text { Liquid }\end{array}$ & $\geq 6$ & $\begin{array}{l}60 \mathrm{tab} \text { of } 5 \mathrm{mg} \$ 33.55^{24} \\
60 \mathrm{tab} \text { of } 5 \mathrm{mg} \$ 268.80^{24} \\
300 \mathrm{ml} \text { of } 10 / 5 \$ 291.00^{24}\end{array}$ \\
\hline Yes & Dexmethylphenidate & Focalin & $2.5,5,10$ & Tablet & $>\underline{6}$ & 60 tab of $5 \mathrm{mg} \$ 46.20^{24}$ \\
\hline Yes & $\begin{array}{l}\text { Dextroamphetamine/ } \\
\text { amphetamine }\end{array}$ & Adderall & $5,7.5,10,12.5,15,20,30$ & Tablet & $\geq 3$ & 60 tab of $5 \mathrm{mg} \$ 72.47^{24}$ \\
\hline
\end{tabular}

Categorization of medications according to WebMD ${ }^{23}$

* $2.5 \mathrm{mg}$ and $7.5 \mathrm{mg}$ only available as brand name Zenzedi 
Table 2. Cost Comparison of Intermediate-acting Stimulants

\begin{tabular}{|c|c|c|c|c|c|c|}
\hline $\begin{array}{l}\text { Availability } \\
\text { as Generic }\end{array}$ & Generic Name & Brand Name & Available Doses & Type & Age & Cost \\
\hline Yes & Methylphenidate ER & $\begin{array}{l}\text { Metadate } \\
\text { ER }\end{array}$ & 20 & Tablet & $\geq 6$ & 30 tab of $20 \mathrm{mg} \$ 41.31^{24}$ \\
\hline Yes & Methylphenidate SR & Ritalin SR & 20 & Tablet & $\geq 6$ & 30 tab of $20 \mathrm{mg} \$ 41.31^{24}$ \\
\hline Yes & Methylphenidate CD & $\begin{array}{l}\text { Metadate } \\
\text { CD }\end{array}$ & $10,20,30,40,50,60$ & Capsule & $\geq 6$ & 30 cap of $20 \mathrm{mg} \$ 112.50^{24}$ \\
\hline
\end{tabular}

Categorization of medications according to WebMD ${ }^{23}$ 
Table 3. Cost Comparison of Long-acting Stimulants

\begin{tabular}{|c|c|c|c|c|c|c|}
\hline $\begin{array}{l}\text { Availability } \\
\text { as Generic }\end{array}$ & Generic Name & Brand Name & Available Doses & Type & Age & Cost \\
\hline Yes & $\begin{array}{l}\text { Dextroamphetamine } \\
\text { ER }\end{array}$ & $\begin{array}{l}\text { Dexedrine } \\
\text { Spansule }\end{array}$ & $5,10,15$ & Capsule & $\geq 6$ & 30 cap of $15 \mathrm{mg} \$ 118.55^{24}$ \\
\hline Yes & Methylphenidate LA & Ritalin LA & $10,20,30,40$ & Capsule & $\geq 6$ & 30 cap of $20 \mathrm{mg} \$ 112.50^{24}$ \\
\hline Yes & Methylphenidate ER & Concerta & $18,27,36,54,72$ & Tablet & $\geq 6$ & 30 tab of $18 \mathrm{mg} \$ 141.30^{24}$ \\
\hline No & $\begin{array}{l}\text { Methylphenidate } \\
\text { transdermal }\end{array}$ & Daytrana & $10,15,20,30$ & Patch & $\geq 6$ & $\begin{array}{l}30 \text { patches of } 20 \mathrm{mg} \\
\$ 246.88^{24}\end{array}$ \\
\hline No & Methylphenidate XR & Quillivant XR & $25 \mathrm{mg} / 5 \mathrm{ml}$ & Liquid & $\geq 6$ & $\begin{array}{l}120 \mathrm{ml} \text { of } 25 \mathrm{mg} / 5 \mathrm{ml} \\
\$ 238.40^{26}\end{array}$ \\
\hline Yes & $\begin{array}{l}\text { Dextroamphetamine/ } \\
\text { amphetamine XR }\end{array}$ & Adderall XR & $5,10,15,20,25,30$ & Capsule & $\geq 6$ & 30 cap of $20 \mathrm{mg} \$ 248.52^{24}$ \\
\hline No & Lisdexamfetamine & Vyvanse & $20,30,40,50,60,70$ & Capsule & $\geq 6$ & 30 cap of $20 \mathrm{mg} \$ 212.70^{24}$ \\
\hline Yes* $^{*}$ & $\begin{array}{l}\text { Dexmethylphenidate } \\
\text { XR }\end{array}$ & Focalin XR & $\begin{array}{l}5,10,15,20,25,30,35, \\
40\end{array}$ & Capsule & $\geq 6$ & 30 cap of $20 \mathrm{mg} \$ 241.50^{24}$ \\
\hline
\end{tabular}

Categorization of medications according to WebMD ${ }^{23}$

* $5 \mathrm{mg}, 10 \mathrm{mg}, 20 \mathrm{mg}, 25 \mathrm{mg}, 35 \mathrm{mg}$ only available as brand Focalin XR 
Table 4. Cost Comparison of Non-stimulants

\begin{tabular}{llllllll}
\hline $\begin{array}{l}\text { Availability } \\
\text { as Generic }\end{array}$ & Classification & Generic Name & $\begin{array}{l}\text { Brand } \\
\text { Name }\end{array}$ & Available Doses & Type & Age & Cost \\
\hline Yes & $\begin{array}{l}\text { Norepinephrine } \\
\text { Reuptake Inhibitors }\end{array}$ & Atomoxetine & Strattera & $\begin{array}{l}10,18,25,40,60, \\
80,100\end{array}$ & Capsule & $\geq 6$ & $\begin{array}{l}30 \mathrm{cap} \text { of } 10 \mathrm{mg} \\
\$ 240.44^{24}\end{array}$ \\
& & & & & & \\
Yes & $\begin{array}{l}\text { Alpha 2 Adrenergic } \\
\text { Agonists }\end{array}$ & Guanfacine & Intuniv & $1,2,3,4$ & Tablet & $\geq 6$ & 30 tab of $1 \mathrm{mg} \$$ \\
& & Clonidine ER & Kapvay & $0.1,0.2$ & Tablet & $\geq 6$ & 30 tab of $0.1 \mathrm{mg}$ \\
& & & & & & & $\$ 141.60^{24}$ \\
\hline
\end{tabular}

Categorization of medications according to $\mathrm{WebMD}^{23}$ 